\title{
Low-Grade Chondrosarcoma of the Posterior Cricoid Plate
}

\author{
Christy M. Moen ${ }^{1}$, Alison E. Lim ${ }^{2}$, Richard B. Townsley ${ }^{3}$ \\ 1. Ear, Nose and Throat, University Hospital Crosshouse, Kilmarnock, GBR 2. Otolaryngology, Queen Elizabeth \\ University Hospital, Glasgow, GBR 3. Otolaryngology - Head and Neck Surgery, University Hospital Crosshouse, \\ Kilmarnock, GBR
}

Corresponding author: Christy M. Moen, christy@moen.co.uk

\begin{abstract}
This case report presents an unusual case of chondrosarcoma arising from the cricoid cartilage of the larynx. Although these are commonly low-grade malignancies, this patient attended an outpatient respiratory clinic with acute airway obstruction, and went on to require a total laryngectomy due to the size of their tumour.
\end{abstract}

Review began 05/21/2021 Review ended 05/26/2021 Published 06/02/2021

(c) Copyright 2021

Moen et al. This is an open access article distributed under the terms of the Creative Commons Attribution License CC-BY 4.0., which permits unrestricted use, distribution, and reproduction in any medium, provided the original author and source are credited.
Categories: Otolaryngology, Pathology, Oncology

Keywords: bone cancer surgery, otolaryngology-head \& neck surgeons, total laryngectomy, partial airway obstruction, multi-disciplinary teams

\section{Introduction}

Chondrosarcoma is the second most common primary bone malignancy, encompassing $10 \%-20 \%$ of cases [1]. Chondrosarcomas can be found in the head and the neck, and can involve the skull base, sinuses and facial bones. Laryngeal chondrosarcomas (LC) make up approximately $3 \%$ of all chondrosarcomas and less than $0.2 \%$ of all laryngeal cancers $[1,2]$. In over $90 \%$ of cases, LCs arise from the hyaline cartilage, with the posterior cricoid cartilage being the most common site of origin [1,2]. LCs have a male to female ratio of approximately 3:1, and commonly present with hoarseness, dyspnoea and neck lump [2]. The aetiology of LCs is unclear; it may be associated with a disorder of the ossification process that may occur when laryngeal cartilage is put under mechanical stress, from the attachments of the intrinsic and extrinsic laryngeal muscles.

LCs tend to be low-grade and less aggressive, compared to chondrosarcomas found in other parts of the body [3]. Histologically it can be challenging to distinguish low-grade chondrosarcoma from benign chondromas. Chondrosarcomas have a better prognosis in comparison with other laryngeal cancers. The largest population-based analysis in the current literature was carried out by Dubal et al [3]. They found oneyear, five-year and 10-year disease-specific survival for their population of 143 patients with Laryngeal chondrosarcomas to be $96.5 \%, 88.6 \%$ and $84.8 \%$, respectively. This was significantly greater in comparison with other laryngeal tumour survival rates.

\section{Case Presentation}

Our patient was a 54-year-old gentleman who originally presented with hoarseness and cough to the Otolaryngology clinic where he had no red flag symptoms and no abnormalities seen on flexible nasoendoscopy (FNE). He was reassured and discharged. He re-presented to primary care 8 months later with a persistent cough and shortness of breath and was referred to the respiratory service. On review in the respiratory clinic, he was found to be stridulous with fixed obstructive pulmonary function tests (PFTs), and an urgent computerised tomography (CT) neck, chest and abdomen were arranged. CT scan found a large, $2.8 \mathrm{~cm}$ craniocaudal $\times 3.8 \mathrm{~cm}$ transverse $\times 3 \mathrm{~cm}$ anteroposterior, submucosal posterior pharyngeal mass with almost complete occlusion of the subglottic airway, with a minimum luminal airway dimension of $8 \mathrm{~mm} \times 3$ $\mathrm{mm}$ (Figures 1,2). 


\section{Cureus}

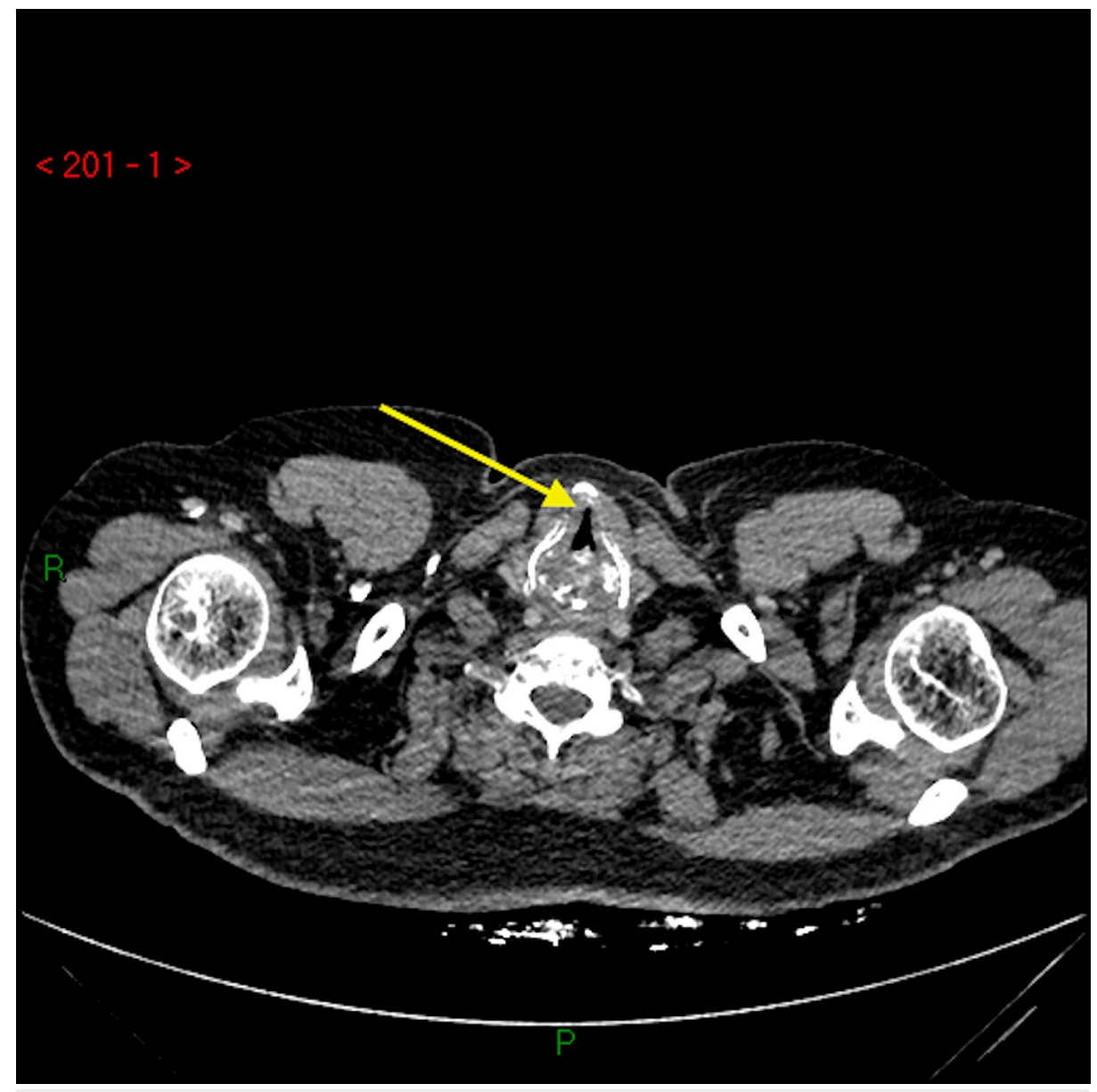

FIGURE 1: CT demonstrating partially obstructed airway.

CT: computed tomography. 


\section{Cureus}

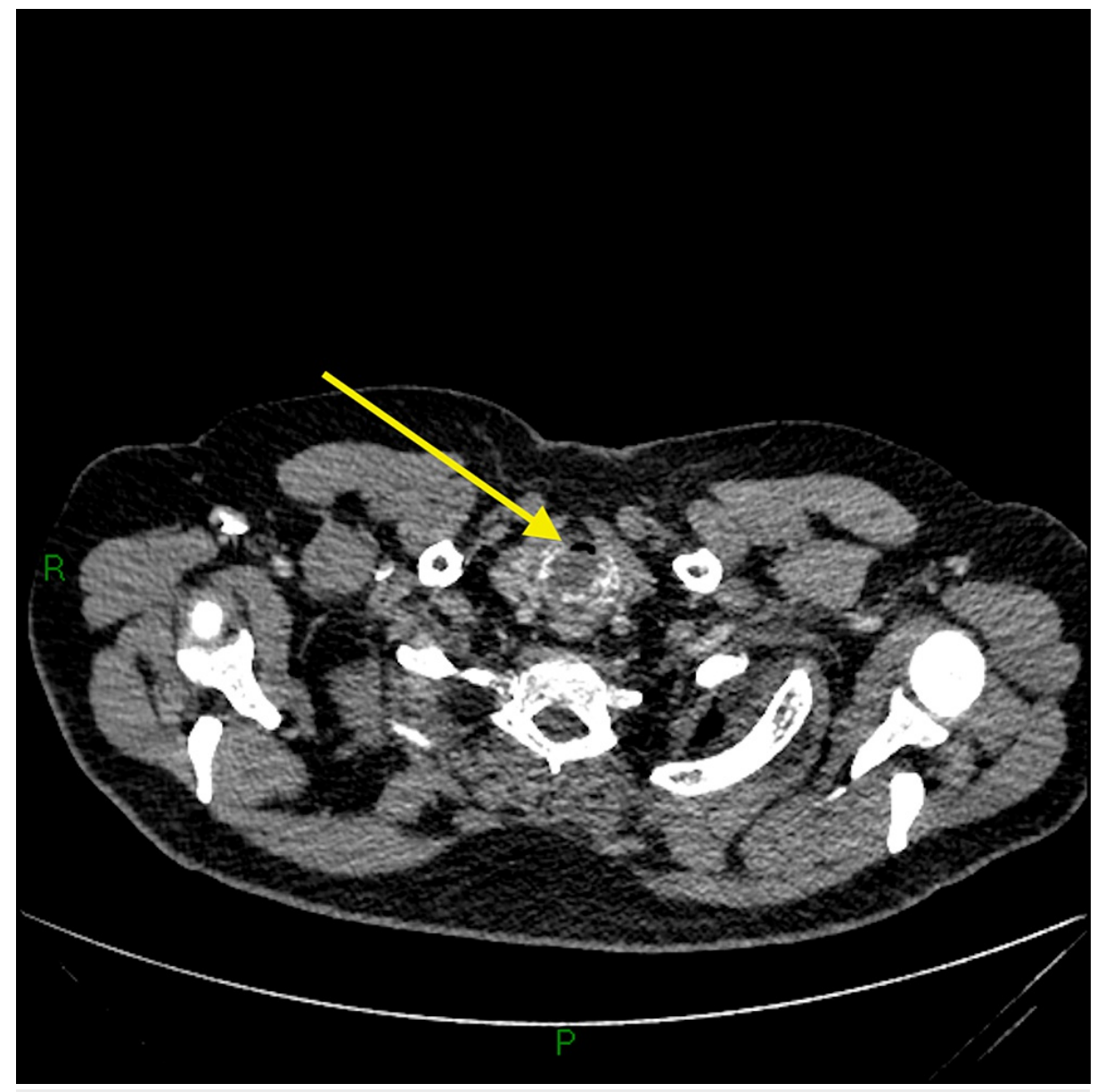

FIGURE 2: CT demonstrating the minimum diameter of the patient's airway.

CT: computed tomography.

This CT image demonstrates the minimum luminal airway dimension found which was $8 \mathrm{~mm} \times 3 \mathrm{~mm}$.

The patient was admitted immediately and then taken to the emergency theatre due to his critical airway. Awake fibreoptic intubation was attempted, but it was not possible to pass a size 5 microendotracheal tube. Local anaesthetic tracheostomy was required to secure the airway before proceeding to general anaesthesia. Biopsies of the large subglottic mass were taken which appeared clinically to be cartilage covered by mucosa. Histopathology results were returned as low-grade chondrosarcoma. He underwent an MRI neck that showed no invasion into local structures or lymph node involvement.

At this point, the patient was referred to the sarcoma multidisciplinary team meeting (MDT). The conclusion of the MDT was that the patient had a T2NOM0, low-grade chondrosarcoma originating from the posterolateral aspect of the cricoid and that surgery would be offered as a curative treatment option. The patient was admitted electively for a total laryngectomy, primary tracheo-oesophageal puncture and placement of a speech valve. Pathology results confirmed a pT2N0 chondrosarcoma, resected with clear margins. The report also noted small nodules at the base of the epiglottis that may have represented chondromas. The patient recovered well post-operatively and passed a barium swallow test to allow for the removal of his nasogastric tube.

The patient is 18 months post treatment with no signs of recurrence and unrestricted swallowing function.

\section{Discussion}

This is a rare case chondrosarcoma of the cricoid cartilage that was picked up on a CT scan carried out by the respiratory team investigating stridor, demonstrating airway obstruction from a subglottic tumour.

Chondrosarcomas are typically slow-growing, low-grade tumours [4]. In this case, the patient presented with symptoms one year before his airway emergency, with no abnormalities seen on examination at the initial 
presentation.

Patients with LCs can present with a variety of symptoms, including hoarseness, shortness of breath, dysphagia, and stridor.

A retrospective case study of $111 \mathrm{LCs}$ found that patients present differently depending on the location of the tumour. Patients with endolaryngeal tumours tended to present with shortness of breath, whereas patients with extralaryngeal tumours tended to present with dysphagia [5]. However, Thompson et al found only three of the $111 \mathrm{LCs}$ studied presented with shortness of breath.

CT scanning is the preferred method of imaging LCs to aid the diagnosis and management planning. Typical LC appearance on a CT scan would show a lesion with 'popcorn-like' calcification that enhances with contrast [6].

Surgery is the primary treatment option for chondrosarcomas, and where possible, laryngeal preserving therapies. Tumours of the appropriate size and location can be excised using endoscopic excision or partial laryngectomy $[7,8]$. If it is not possible to carry out local resection, a total laryngectomy may be required to ensure complete excision of the tumour is achieved.

Of note, Thompson et al [5] found only 1.9\% of their patients went on to develop metastases (lung, bone, and liver).

\section{Conclusions}

We have demonstrated an unusual case of chondrosarcoma arising from the cricoid cartilage of the larynx. Although these are commonly low-grade malignancies, this patient presented with acute airway obstruction and required total laryngectomy for a large tumour. Due to the rarity of these cases, it is important to discuss them at regional or national MDTs to ensure the development of experience and expertise of their management.

\section{Additional Information \\ Disclosures}

Human subjects: Consent was obtained or waived by all participants in this study. Conflicts of interest: In compliance with the ICMJE uniform disclosure form, all authors declare the following: Payment/services info: All authors have declared that no financial support was received from any organization for the submitted work. Financial relationships: All authors have declared that they have no financial relationships at present or within the previous three years with any organizations that might have an interest in the submitted work. Other relationships: All authors have declared that there are no other relationships or activities that could appear to have influenced the submitted work.

\section{References}

1. Gripp S, Pape H, Schmitt G: Chondrosarcoma of the larynx: the role of radiotherapy revisited--a case report and review of the literature. Cancer. 1998, 82:108-15. 10.1002/(sici)1097-0142(19980101)82:1<108::aidcncr 13>3.0.c0;2-6

2. Chin OY, Dubal PM, Sheikh AB, Unsal AA, Park RC, Baredes S, Eloy JA: Laryngeal chondrosarcoma: a systematic review of 592 cases. Laryngoscope. 2017, 127:430-9. 10.1002/lary.26068

3. Dubal PM, Svider PF, Kanumuri VV, Patel AA, Baredes S, Eloy JA: Laryngeal chondrosarcoma: a populationbased analysis. Laryngoscope. 2014, 124:1877-81. 10.1002/lary.24618

4. Policarpo M, Taranto F, Aina E, Aluffi PV, Pia F: Chondrosarcoma of the larynx: a case report. Acta Otorhinolaryngol Ital. 2008, 28:38-41.

5. Thompson LD, Gannon FH: Chondrosarcoma of the larynx: a clinicopathologic study of 111 cases with a review of the literature. Am J Surg Pathol. 2002, 26:836-51. 10.1097/00000478-200207000-00002

6. Sauter A, Bersch C, Lambert KL, Hörmann K, Naim R: Chondrosarcoma of the larynx and review of the literature. Anticancer Res. 2007, 27:2925-9.

7. Aydin S, Demir MG, Basak K: Chondrosarcoma of the larynx: case report. J Otolaryngol Forecast. 2019, $2: 1008$.

8. Oliveira JF, Branquinho FA, Monteiro AR, Portugal ME, Guimarães AM: Laryngeal chondrosarcoma--ten years of experience. Braz J Otorhinolaryngol. 2014, 80:354-8. 10.1016/j.bjorl.2014.05.004 